\title{
Elderly-onset hereditary pulmonary alveolar proteinosis and its cytokine profile
}

\author{
Masayuki Ito ${ }^{1}$, Kazuyuki Nakagome², Hiromitsu Ohta², Keiichi Akasaka', Yoshitaka Uchida², Atsushi Hashimoto', \\ Ayako Shiono ${ }^{2}$, Toshinori Takada' ${ }^{1}$, Makoto Nagata², Jun Tohyama ${ }^{3}$, Koichi Hagiwara ${ }^{4}$, Minoru Kanazawa², \\ Koh Nakata ${ }^{1}$ and Ryushi Tazawa ${ }^{*}$ (D)
}

\begin{abstract}
Background: Pulmonary alveolar proteinosis (PAP) is a rare lung disease characterized by surfactant accumulation, and is caused by disruption of granulocyte/macrophage colony-stimulating factor (GM-CSF) signaling. Abnormalities in CSF2 receptor alpha (CSF2RA) were reported to cause pediatric hereditary PAP. We report here the first case of CSF2RA-mutated, elderly-onset hereditary (h) PAP.

Case presentation: The patient developed dyspnea on exertion, and was diagnosed with PAP at the age of 77 years, based on findings from chest computed tomography scan and bronchoalveolar lavage. She tested negative for GM-CSF autoantibodies, with no underlying disease. Her serum GM-CSF level was elevated (91.3 pg/ $\mathrm{mL}$ ), indicating GM-CSF signaling impairment and genetic defects in the GM-CSF receptor. GM-CSF-stimulated phosphorylation in signal transducer and activator of transcription 5 (STAT5) was not observed, and GM-CSF-Ra expression was defective in her blood cells. Genetic screening revealed a homozygous, single-base C $>$ T mutation at nt 508-a nonsense mutation that yields a stop codon (Q170X) -in exon 7 of CSF2RA. High-resolution analysis of single nucleotide polymorphism array confirmed a 22.8-Mb loss of heterozygosity region in Xp22.33p22.11, encompassing the CSF2RA gene. She was successfully treated with whole lung lavage (WLL), which reduced the serum levels of interleukin (IL)-2, IL-5, and IL-17, although IL-3 and M-CSF levels remained high.

Conclusions: This is the first known report of elderly-onset hPAP associated with a CSF2RA mutation, which caused defective GM-CSF-Ra expression and impaired signaling. The analyses of serum cytokine levels during WLL suggested that GM-CSF signaling might be compensated by other signaling pathways, leading to elderly-onset PAP.
\end{abstract}

Keywords: Hereditary pulmonary alveolar proteinosis, GM-CSF, GM-CSF receptor, Elderly onset, Cytokine profile

\section{Background}

The lungs reduce alveolar surface tension by producing pulmonary surfactants, which are essential for maintaining smooth breathing. The levels of pulmonary surfactants are balanced between their production by alveolar epithelial cells and clearance by alveolar macrophages. Granulocyte/ macrophage colony-stimulating factor (GM-CSF), a 23-kDa monomeric glycoprotein, regulates various functions of the alveolar macrophages, including surfactant catabolism, and

\footnotetext{
* Correspondence: ryushi@med.niigata-u.ac.jp

${ }^{1}$ Bioscience Medical Research Center, Niigata University Medical and Dental Hospital, Niigata 951-8520, Japan

Full list of author information is available at the end of the article
}

plays an important role in pulmonary surfactant homeostasis.

Pulmonary alveolar proteinosis (PAP) is a rare lung disease characterized by the accumulation of surfactant proteins, which causes progressive respiratory insufficiency [1-3]. Three clinically and etiologically distinct forms of PAP are acknowledged: autoimmune, secondary, and congenital. More than $90 \%$ of PAP cases are autoimmune type (aPAP). aPAP is specifically associated with high levels of a neutralizing autoantibody against GM-CSF that impairs GM-CSF-dependent surfactant clearance mediated by alveolar macrophages [4-8].

The GM-CSF signal is conveyed through the GM-CSF receptor on cell surfaces, via signal transducer and 
activator of transcription 5 (STAT5). The GM-CSF receptor is a dodecameric complex consisting of a ligand-specific alpha (GM-CSF-R $\alpha, C D 161)$ and a beta (GM-CSF-R $\beta$, CD131) subunit, which is shared with the interleukin (IL)-3 and IL-5 receptors $[9,10]$.

Recently, it has been reported that abnormalities in the GM-CSF-R $\alpha$-encoding alleles (CSF2RA) cause hereditary (h) PAP, presenting as insidious, progressive dyspnea in children; and that increased serum GM-CSF is useful to identify such individuals [11-15]. However, no elderly-onset case with defect in the GM-CSF receptor was reported until date. In the present report, we describe the oldest case of hPAP until date, whose symptoms occurred at the age of 77 . The patient suffered severe hypoxemia, underwent a single whole lung lavage (WLL), and showed dramatic improvement.

\section{Methods}

\section{Measurement of GM-CSF autoantibody levels}

The concentration of GM-CSF autoantibodies in the bronchoalveolar lavage fluid (BALF) or serum were measured by sandwich enzyme-linked immunosorbent assay (ELISA), performed as described previously [16, 17], with slight modifications. In brief, 96-well microtiter plates (Maxisorp, Nalge Nunc International, Rochester, NY, U.S.A.) were coated with recombinant human (rh) GM-CSF $[1 \mu \mathrm{g} / \mathrm{mL}$ in phosphate-buffered saline (PBS)] at $4{ }^{\circ} \mathrm{C}$ overnight, washed with PBS (containing $0.1 \%$ Tween 20), and blocked with Stabilcoat (Surmodics, Eden Prairie, MN, U.S.A.) at room temperature for $1 \mathrm{~h}$. The BALF sample was diluted to $1 / 100$ (for patients with PAP) in sample dilution buffer [PBS, 1\% (w/v) goat serum, $0.1 \%(\mathrm{v} / \mathrm{v})$ Tween 20 ], and $50 \mu \mathrm{L}$ of the diluted sample was incubated in triplicate wells at room temperature for $40 \mathrm{~min}$. The plates were washed and after addition of ammonium acetate (10 mM, pH 5.0), incubated at room temperature for $15 \mathrm{~min}$ to prevent non-specific binding. Next, horseradish peroxidaseconjugated goat anti-human IgG (diluted to $1 / 3000$ with sample dilution buffer) was added, and the plates incubated at room temperature for $30 \mathrm{~min}$. Bound IgG was detected using 3,3,5,5-tetramethylbenzidine substrate solution $(50 \mu \mathrm{L}$; Bethyl Laboratories, Montgomery, TX, U.S.A.), followed by addition of $1 \mathrm{~N} \mathrm{H}_{2} \mathrm{SO}_{4}$. The absorbance was read at $450 \mathrm{~nm}$ using a microplate reader (Biorad, Hercules, CA, U.S.A.).

\section{Immunoblotting}

Peripheral blood mononuclear cells (PBMCs) were cultured on 24 -well culture plates at $5 \times 10^{5}$ cells/well. The cells were incubated with GM-CSF $(0-1000 \mathrm{ng} / \mathrm{mL})$ for 15 min. Lysed protein extracts were separated by sodium dodecyl sulphate polyacrylamide gel electrophoresis, transferred to a polyvinylidene fluoride membrane, and assessed by standard western blotting procedures, as previously described [5]. Primary antibodies used for detection included anti-human GM-CSF-R $\alpha$ (Santa Cruz Biotechnology, Santa Cruz, CA, U.S.A.), GM-CSF-R $\beta c$, anti-human STAT5 (Santa Cruz Biotechnology) and phospho (p)-STAT5 (Millipore, Billerica, MA, U.S.A.) antibodies. Peroxidase-labeled anti-rabbit IgG antibody (Sigma-Aldrich, St. Louis, MO, U.S.A.) was used as secondary antibody and the bands were visualized with ECL plus (GE Healthcare, Waukesha, WI, U.S.A.). To enhance the signal, immunoreaction enhancer solution (Can Get Signal, TOYOBO, Osaka, Japan) was used according to the manufacturer's instructions. Actin was measured as loading control for each sample, using antiactin antibody (Santa Cruz Biotechnology).

\section{Flow cytometry}

Phosphorylated STAT5 detection by flow cytometry was described previously [18]. Heparinized fresh whole blood was incubated with $50 \mathrm{ng} / \mathrm{mL}$ rhGM-CSF and IL-2 for $20 \mathrm{~min}$ at $37{ }^{\circ} \mathrm{C}$ and fixed. Next, red blood cells were lysed in Fix/Lyse buffer (BD Bioscience, Franklin Lakes, NJ, U.S.A.) for $15 \mathrm{~min}$ at $37{ }^{\circ} \mathrm{C}$. White blood cells were collected by centrifugation and fixed in ice-cold methanol at $-20{ }^{\circ} \mathrm{C}$ for $1 \mathrm{~h}$. After centrifugation, the cells were suspended in 3\% fetal bovine serum/0.01\% $\mathrm{NaN}_{3} / \mathrm{PBS}$ solution and incubated with Alexa Fluor 647-labeled anti-pSTAT5 (BD Bioscience). Cells with phosphorylated STAT5 were detected by flow cytometry (Cell Analyzer, Sony, Tokyo, Japan).

\section{Reverse transcription polymerase chain reaction (RT-PCR)}

Total RNA was extracted from blood mononuclear cells, using RNA Easy Plus Mini Kit (QIAGEN, Hilden, Germany), and was reverse transcribed with random hexamer primers and the SuperScript III First-Stand Synthesis System for RT-PCR (Invitrogen, Carlsbad, CA, U.S.A.). The cDNAs were subjected to semiquantitative RT-PCR analysis with PrimerSTAR GXL DNA polymerase (Takara Bio, Otsu, Japan) with CSF2RA-specific primers (Additional file 1: Table S1).

\section{Nucleotide sequencing}

The PCR was performed to generate products spanning exons and flanking sequences of the CSF2RA gene, which were purified using the QIAquick DNA extraction kit (QIAGEN) and subjected to nucleotide sequencing using the BigDye Terminator v3.1 cycle sequencing kit (Applied Biosystems, Foster City, CA, U.S.A.) and CSF2RA-specific primers (Supplementary Table). The resulting sequences were compared with published sequences for CSF2RA (GenBank/EMBL/DDBJ under accession number NM_006140). 


\section{Array-comparative genomic hybridization (aCGH)} aCGH analysis was performed using the CytoScan HD array kit according to the manufacturer's protocol (Affymetrix, Santa Clara, CA, U.S.A.). Genetic counseling was performed for the patient before and after genetic analyses.

\section{Cytokine assay}

IL-2, IL-3, IL-4, IL-5, IL-17, and M-CSF were analyzed using ELISA kits (CUSABIO, Wuhan, Hubei Province, P.R. China) according to the manufacturer's protocol.

\section{Case presentation}

A previously healthy, 77-year-old, non-smoking woman, with normal chest radiograph at a medical check-up three years earlier, was referred to our hospital for dyspnea on exertion, which occurred one month earlier. She was a homemaker with no remarkable family history.

A physical examination revealed no abnormality. A chest X-ray and computed tomography (CT) scan indicated ground glass opacity in both lower lungs, of which crazy-paving appearance was confirmed upon highresolution CT scan (Fig. 1a, b). Laboratory studies revealed elevated levels of serum KL-6, a mucin-like protein $(4314 \mathrm{U} / \mathrm{mL})$, surfactant protein D (SP-D; $400 \mathrm{ng} /$ $\mathrm{mL}$ ), and carcinoembryonic antigen (CEA; $13.2 \mathrm{ng} / \mathrm{mL})$; and negative test results for beta-D glucan and Aspergillus antigen. Analysis of arterial blood gas while breathing room air revealed a low partial pressure of oxygen $\left(\mathrm{PaO}_{2}\right)$ of $47 \mathrm{mmHg}$ just before WLL. BALF presented a milky appearance with lymphocytosis (macrophages, $64 \%$ of total cells; lymphocytes, 26\%; neutrophils 9\%; eosinophils, 1\%), foamy macrophages, and amorphous materials (Fig. 1c, d).

The patient was diagnosed with PAP, based on typical findings from chest CT scan and bronchoalveolar lavage. She had no underlying disease. GM-CSF autoantibodies were not detected in either the serum or the BALF. On the other hand, a high level of serum GM-CSF was detected $(91.3 \mathrm{pg} / \mathrm{mL})$, indicating disrupted GM-CSF signaling and genetic defects in the GM-CSF receptor. We decided to screen for GM-CSF signaling abnormalities because GM-CSF concentration was extremely high in her BALF.

To investigate signaling activated by GM-CSF in the PBMCs, we first probed the presence of phosphorylated STAT5 upon stimulating the PBMCs with increasing concentrations of GM-CSF $(0-1000 \mathrm{ng} / \mathrm{mL})$. Phosphorylated STAT5 was observed in the control but not in the patient PBMCs, indicating defective GM-CSF signaling in the latter (Fig. 2). To confirm this result, we performed flow cytometry. The results also showed that expression of phosphorylated STAT5 was not observed on stimulation of peripheral blood mononuclear cells of the patient with GM-CSF, while expression of phosphorylated STAT5 was observed on stimulation of those of the control with GM-CSF as
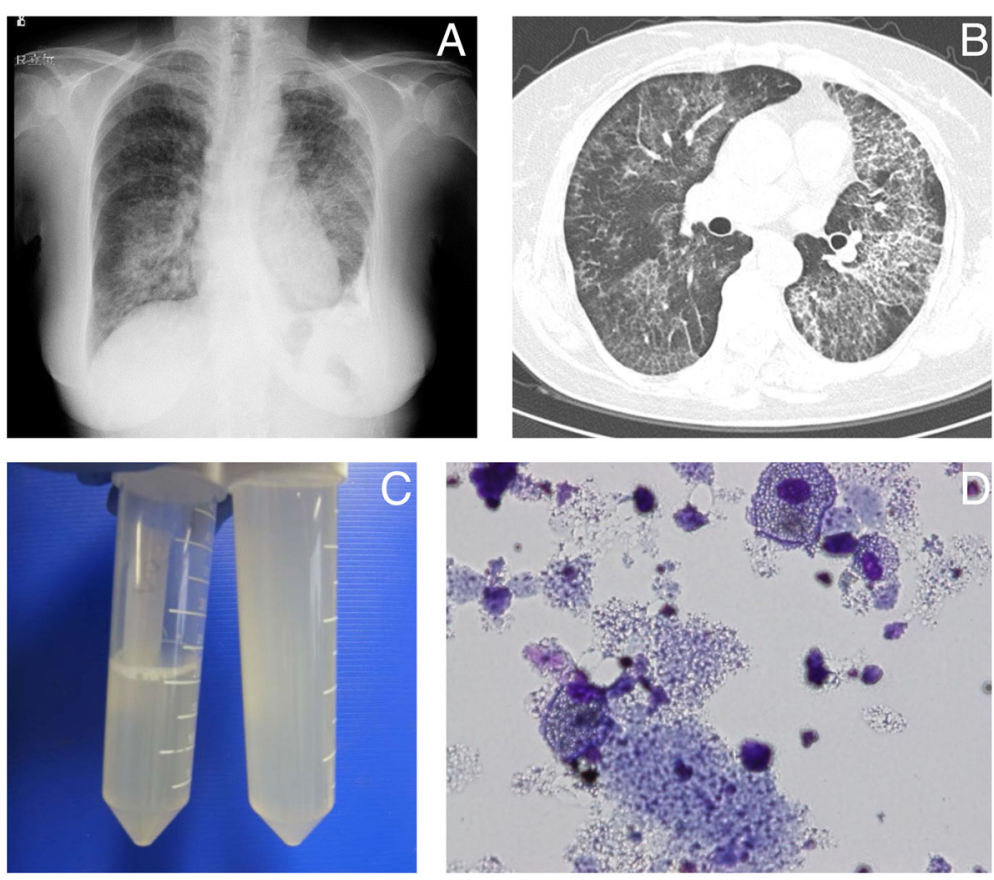

Fig. 1 a Chest radiogram of the patient. $\mathbf{b}$ High-resolution computed tomogram of the patient. c BALF presented a milky appearance with lymphocytosis (26\%). d Foamy macrophages and amorphous materials in BALF of the patient 


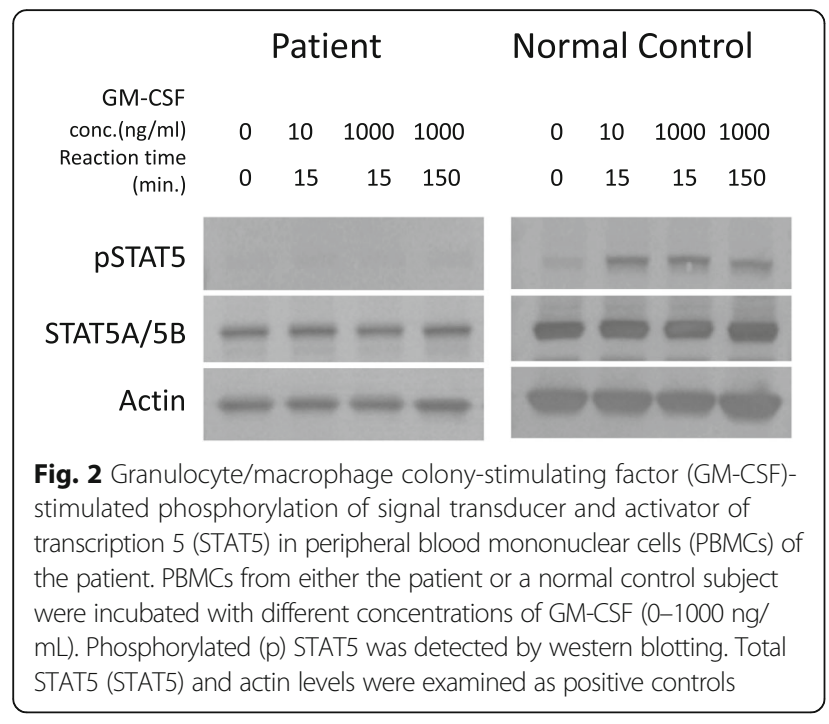

well as on stimulation of those of both with IL-2 (Fig. 3).

Next, we investigated the expression of the $\alpha$ and $\beta$ chains of the GM-CSF receptor on the PBMCs, by western blotting. The expression of GM-CSF-R $\beta$ and IL-3R $\alpha$ on patient monocytes was comparable with that on the controls; however, expression of GM-CSF-R $\alpha$ was not detected in the former (Fig. 4). The result was further confirmed by RT-PCR (Fig. 5). Together, these results indicated defects in the molecules that transmit GMCSF signals to STAT5.

cDNAs of CSF2RB, reverse-transcribed from the mRNA of the patient PBMCs, harbored no mutations or deletions (data not shown). PCR amplicons for each exon of CSF2RA from the patient PBMCs were screened for their nucleotide sequences, revealing a homozygous single-base mutation $\mathrm{C}>\mathrm{T}$ at nt 508 in exon 7 (Fig. 6). This mutation was a nonsense mutation that gave rise to a stop codon (Q170X).

Further evaluation by aCGH demonstrated a $22.8-\mathrm{Mb}$ region of loss of heterozygosity (LOH) in Xp22.33p22.11, encompassing the CSF2RA gene.

To investigate the functional background underlying the late onset of the symptoms in the present case, we compared the changes in serum levels of IL-2, IL-3, IL4, IL-5, IL-17, and M-CSF before and after WLL that improved $\mathrm{PaO}_{2}$ by $26 \mathrm{mmHg}$ (Fig. 7). The IL-2, IL-4, and IL-5 levels were remarkably reduced post WLL,

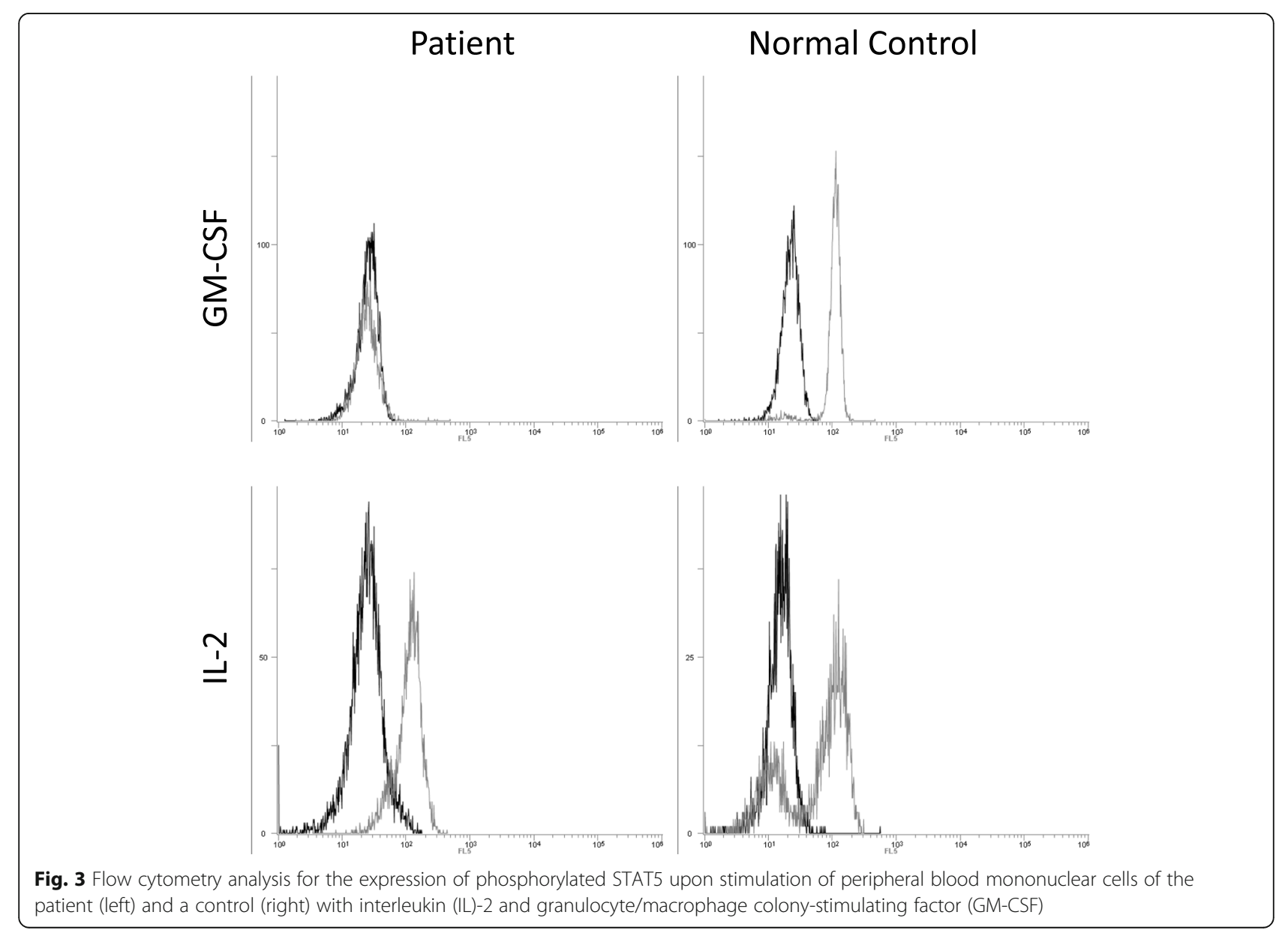




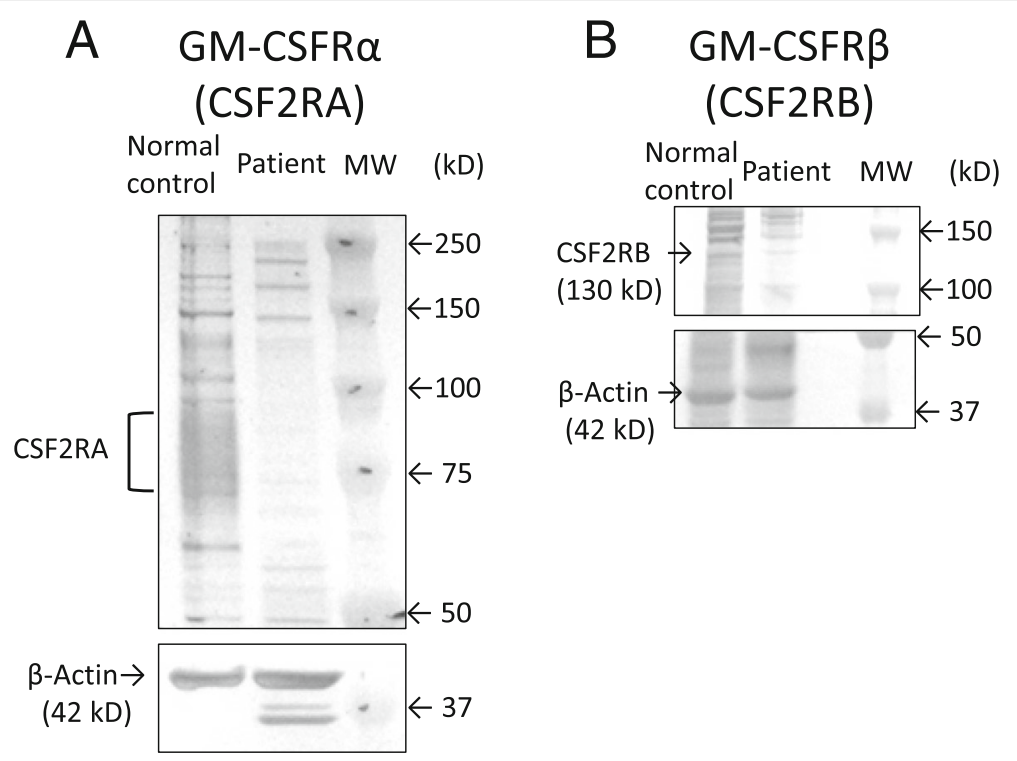

Fig. 4 a Detection of granulocyte/macrophage colony-stimulating factor receptor alpha (GM-CSFRa; upper panel), and actin (lower panel) in peripheral blood monocytic cells of the patient (PBMCs) (left), and a control (middle), by western blotting with specific antibodies. GM-CSF-Ra was not detected in the patient (left lane) but was observed for the control (middle lane). b Detection of GM-CSFRß (upper panel) and actin (lower panel) in PBMCs of the patient (left), and a control (right), by western blotting with specific antibodies. Bands for GM-CSF-R $\beta$ and actin were detected for both the patient and the control

after which they gradually increased. IL-17 levels remained low for about 7 months after WLL. On the other hand, IL-3 and M-CSF levels were marginally altered post WLL. In addition, the serum level of GM-CSF demonstrated a tendency to decrease after WLL.

\section{Discussion}

The present study reports the first case of elderly-onset hPAP with CSF2RA mutation. The patient had a

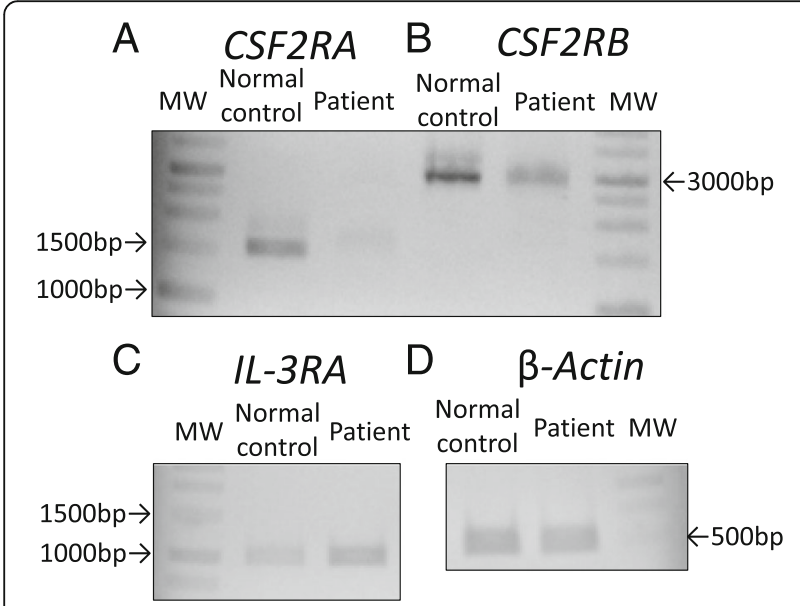

Fig. 5 Reverse transcription polymerase chain reaction for mRNA obtained from peripheral blood mononuclear cells of the patient and a normal control, using primers specific for CSF2A, CSF2B, IL3RA, and $A C T B$ homozygous mutation that changed a codon for glutamine 170 to a stop codon, disrupting normal expression of GM-CSF-R $\alpha$ and proper signaling of GM-CSF. We previously reported a case of adult-onset hPAP that was due to homozygous nonsense mutation in the CSF2RB gene [15]. The present case, where the patient developed hPAP in her seventies, is the oldest until date for this disease (Table 1). Interestingly, her mutation was in exon

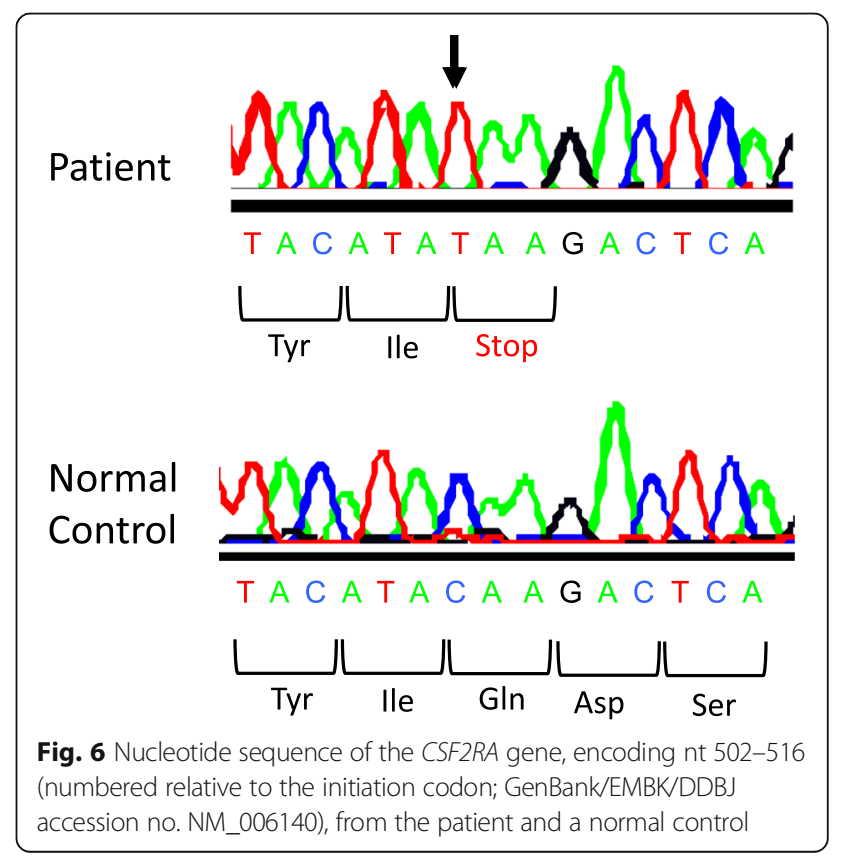




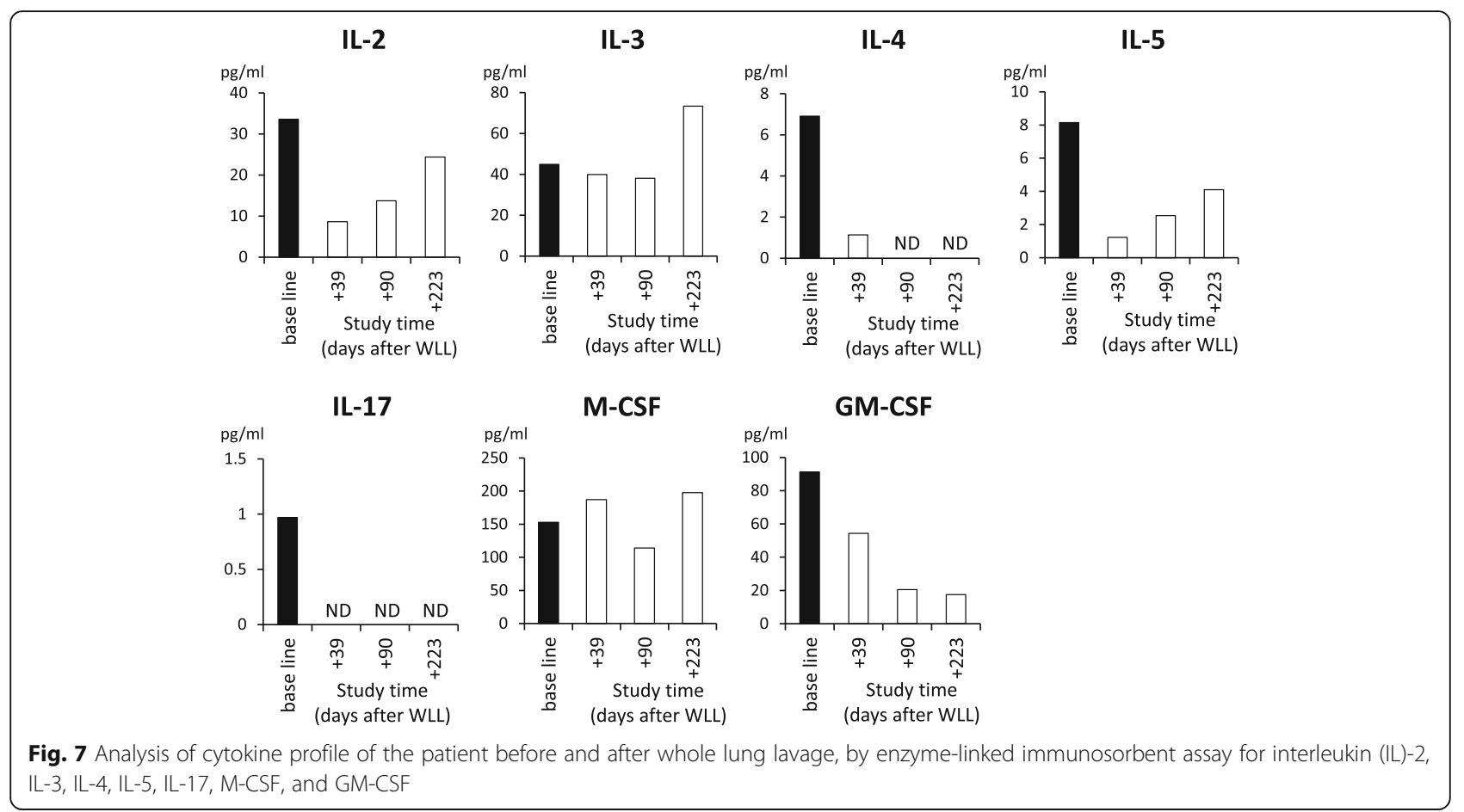

7 of the CSF2RA gene, in which the first child case for hPAP also had a mutation [11].

To investigate the background of the late-onset hPAP in this case, we studied her serum profile for various cytokines. The patient was treated with WLL, which greatly improved oxygenation indices and reduced the serum levels of various cytokines including IL-2, IL-5, and IL-17, indicating relieved inflammatory activation of Th1 and Th17 lymphocytes. In contrast, the serum levels of IL-3 and M-CSF remained high after WLL, indicating

Table 1 Clinical characteristics of reported cases of hereditary pulmonary alveolar proteinosis

\begin{tabular}{|c|c|c|c|}
\hline Characteristics & $\begin{array}{l}\text { Present case } \\
\text { Adult onset }\end{array}$ & $\begin{array}{l}\text { Tanaka et al. } \\
\text { Adult onset }\end{array}$ & $\begin{array}{l}\text { Junne et al. } \\
\text { Juvenile }(n=20)\end{array}$ \\
\hline Sex & Female & Female & $85 \%$ (Female) \\
\hline $\begin{array}{l}\text { Age at symptom } \\
\text { onset (yr) }\end{array}$ & 77 & 35 & $0.2-19$ \\
\hline Prognosis & Good & Poor & Good \\
\hline GM-CSF (pg/mL) & 86.61 & 124.8 & Elevated \\
\hline $\begin{array}{l}\text { GM-CSF antibody } \\
(\mu \mathrm{g} / \mathrm{mL})\end{array}$ & ND & ND & ND \\
\hline Mutated gene & CSF2RA & CSF2RB & CSF2RA \\
\hline \multirow[t]{4}{*}{ WLL therapy } & responded & Worsened & Improved 64\% \\
\hline & & & Unchanged $14 \%$ \\
\hline & & & Worsened 0\% \\
\hline & & & Deceased 7\% \\
\hline
\end{tabular}

GM-CSF granulocyte/macrophage colony-stimulating, ND not detected, CSF2RA, CSF2 receptor alpha, CSF2RB, CSF2 receptor beta, WLL whole lung lavage that they might be needed even after the treatment procedure. The high activities of IL-3 and M-CSF in the patient might be associated with the clinical course of her late-onset hPAP.

It is notable that GM-CSF, IL-3, IL-4, and IL-5 are coded by neighbor genes located at $5 \mathrm{q} 31.1$, and affect the functions of monocytes and macrophages. The serum levels of IL-4, IL-5, and GM-CSF decreased after WLL, while IL-3 levels remained high. Receptors of IL-3 and IL-5 share beta chains with that of GM-CSF. Disruption of the alpha chain of the GM-CSF receptor might affect stoichiometry of the common beta chains, presumably causing substantial alterations in IL-3 and IL-5 signaling. Interestingly, WLL differentially affected the levels of these cytokines in the serum of the patient in this study.

Similar to previous pediatric hPAP cases, the present case also demonstrated a high level of serum GM-CSF and a good response to WLL (Table 1). The increased serum GM-CSF levels might be useful for identifying patients with childhood as well as adult hPAP $[19,20]$. The present case showed remarkable response to WLL with regard to oxygenation indices and serum levels of various cytokines that might be associated with compensation of GM-CSF signaling.

\section{Conclusions}

This is the first known report of elderly-onset hPAP associated with a genetic defect in CSF2RA, which caused defective GM-CSF-R $\alpha$ expression and impaired signaling. These results suggest that GM-CSF signaling is 
compensated by other signaling pathways, leading to elderly-onset or non-symptomatic PAP.

\section{Additional file}

Additional file 1: Table S1. A list of primers for PCR and sequencing (DOCX $17 \mathrm{~kb}$ )

\section{Abbreviations}

CSF2RA: Colony stimulating factor 2 receptor alpha chain; ELISA: Enzymelinked immunosorbent assay; GM-CSF: Granulocyte/macrophage-colony stimulating factor; hPAP: Hereditary PAP PAP, pulmonary alveolar proteinosis; IL-2: Interleukin2

\section{Acknowledgements}

The authors thank the investigators and patients who participated in this study; Yuko Ito for measurement of GM-CSF autoantibody levels; and Marie Mori for help with data analysis.

\section{Funding}

This work was supported in part by grants from the Japanese Ministry of Education, Science and Culture, Ministry of Health, Labor, and Welfare of Japan (H21-Nanchi-Ippan-161, to KN, and H24-Rinkensui-Ippan-003 to RT), Grant-in-Aid for Scientific Research (Category B $15 \mathrm{H} 04829$ to KN, Category C 22590852 to RT), and Japan Agency for Medical Research and Development (16ek0109063h0003 to KN, RT).

\section{Availability of data and materials}

The nucleotide sequences from the PCR amplicons for each coding exon of CSF2RA from the patient PBMCs, including a homozygous single-base mutation of c.581C > T (p.Q170X), has been registered (GenBank/EMBL/DDBJ accession number LC172167)

\section{Authors' contributions}

Conception and design: MI, KaN, KH, MK, KoN, RT; Analysis and interpretation: $\mathrm{Ml}, \mathrm{KaN}, \mathrm{KH}, \mathrm{KoN}, \mathrm{RT}$; Drafting and reviewing the manuscript for intellectual content: MI, KaN, MK, KoN, RT; Genetic consideration: KaN, HO, JT, KH, RT; Patient observation and acquisition of data: $\mathrm{KN}, \mathrm{HO}, \mathrm{KA}, \mathrm{YU}, \mathrm{AH}, \mathrm{AS}, \mathrm{T}, \mathrm{MN}$, $\mathrm{KH}, \mathrm{MK}$. All authors read and approved the final manuscript.

\section{Competing interests}

Authors have no competing interest to declare regarding this study.

\section{Consent for publication}

Written informed consent was obtained from the patient's son for publication of this case report, as the patient recently died of gastric cancer.

\section{Ethics approval and consent to participate}

This study was approved by the institutional review boards of Saitama Medical University and Niigata University. Written informed consent to participate in this study was obtained from the patient.

\section{Author details}

'Bioscience Medical Research Center, Niigata University Medical and Dental Hospital, Niigata 951-8520, Japan. ${ }^{2}$ Department of Respiratory Medicine, Saitama Medical University, Saitama, Japan. ${ }^{3}$ National Hospital Organization Nishi-Niigata Chuo Hospital, Niigata, Japan. ${ }^{4}$ Department of Respiratory Medicine, Jichi Medical University, Tochigi, Japan.

\section{Received: 20 September 2016 Accepted: 7 February 2017}

\section{Published online: 17 February 2017}

\section{References}

1. Rosen $\mathrm{SH}$, Castleman B, Liebow AA. Pulmonary alveolar proteinosis. N Engl J Med. 1958;258:1123-42.

2. Seymour JF, Presneill JJ. Pulmonary alveolar proteinosis: progress in the first 44 years. Am J Respir Crit Care Med. 2002;166:215-35.

3. Trapnell BC, Whitsett JA, Nakata K. Pulmonary alveolar proteinosis. N Engl J Med. 2003;349:2527-39.
4. Kitamura T, Tanaka N, Watanabe J. Uchida, Kanegasaki S, Yamada Y, Nakata K. Idiopathic pulmonary alveolar proteinosis as an autoimmune disease with neutralizing antibody against granulocyte/macrophage colony-stimulating factor. J Exp Med. 1999;190:875-80.

5. Uchida K, Nakata K, Trapnell BC, Terakawa T, Hamano E, Mikami A, Matsushita I, Seymour JF, Oh-Eda M, Ishige I, Eishi Y, Kitamura T, Yamada Y, Hanaoka K, Keicho N. High-affinity autoantibodies specifically eliminate granulocyte-macrophage colony-stimulating factor activity in the lungs of patients with idiopathic pulmonary alveolar proteinosis. Blood. 2004; 103:1089-98.

6. Dranoff G, Crawford AD, Sadelain M, Ream B, Rashid A, Bronson RT Dickersin GR, Bachurski CJ, Mark EL, Whitsett JA, Mulligan RC. Involvement of granulocyte-macrophage colony-stimulating factor in pulmonary homeostasis. Science. 1994;264(5159):713-16.

7. Stanley E, Lieschke GJ, Grail D, Metcalf D, Hodgson G, Gall JA, Maher DW, Cebon J, Sinickas V, Dunn AR. Granulocyte/macrophage colony-stimulating factor-deficient mice show no major perturbation of hematopoiesis but develop a characteristic pulmonary pathology. Proc Natl Acad Sci U S A 1994;91:5592-96.

8. Sakagami T, Beck D, Uchida K, Suzuki T, Carey BC, Nakata K, Keller G, Wood RE, Wert SE, Ikegami M, Whitsett JA, Luisetti M, Davies S, Krischer JP, Brody A, Ryckman F, Trapnell BC. Patient-derived granulocyte/macrophage colonystimulating factor autoantibodies reproduce pulmonary alveolar proteinosis in nonhuman primates. Am J Respir Crit Care Med. 2010;182:49-61.

9. Burgess AW, Camakaris J, Metcalf D. Purification and properties of colonystimulating factor from mouse ling-conditioned medium. J Biol Chem. 1977; 252:1998-2003.

10. Nishinakamura R, Nakayama N, Hirabayashi $Y$, Inoue T, Aud D, McNell T, Azuma S, Yoshida S, Toyoda Y, Arai K, Miyajima A, Murray R. Mice deficient for the IL-3/CM-CSF/IL-5 beta c receptor exhibit lung pathology and impaired immune response, white beta IL3 receptor-deficient mice are normal. Immunity. 1995;2:211-22.

11. Suzuki T, Sakagami T, Rubin BK, Nogee LM, Wood RE, Zimmerman SL, Smolarek T, Cary BC, Stevens C, Loo JCM, Trapnell BC. Familial pulmonary alveolar proteinosis caused by mutation in CSF2RA. J Exp Med. 2008:205:2703-10.

12. Martinez-Moczygemba M, Doan ML, Elidemir O, Fan LL, Cheung SW, Lei JT, Moore JP, Tavana G, Lewis LR, Zhu Y, Muzny DM, Gibbs RA, Huston DP. Pulmonary alveolar proteinosis caused by deletion of the GN-CSF alpha gene in the $X$ chromosome pseudoautosomal region 1. J Exp Med. 2008;205:2711-6.

13. Dirksen U, Nishimura R, Groneck P, Hattenhorst U, Nogee L, Murray R, Burdach S. Human pulmonary alveolar proteinosis associated with a defect in CM-CSF/LL-3/IL-5 common beta chain expression. J Clin Invest. 1997:100:2211-7.

14. Bewing B, Wang XD, Kirsten D, Dalhoff K, Schafer H. GM-CSF and GM-CSF beta $\mathrm{C}$ receptor in adult patients with pulmonary aloveolar proteinosis. Eur Respir J. 2000;15:350-7.

15. Tanaka T, Motoi N, Tsuchihashi Y, Tazawa R, Kaneko C, Nei T, Yamamoto T, Hayashi T, Tagawa T, Nagayasu T, Kuribayashi F, Ariyoshi K, Nakata K, Morimoto K. Adult-onset hereditary pulmonary alveolar proteinosis caused by a single-base deletion in CSF2RB. J Med Genet. 2011;48:205-9.

16. Uchida K, Beck DC, Yamamoto T, Berclaz PY, Abe S, Staudt MK, Carey BC, Filippi MD, Wert SE, Denson LA, Puchalski JT, Hauck DM, Trapnell BC. GMCSF autoantibodies and neutrophil dysfunction in pulmonary alveolar proteinosis. N Engl J Med. 2007;356:567-79.

17. Schoch OD, Schanz U, Koller M, Nakata K, Seymour JF, Russi EW, Boehler A. BAL findings in a patient with pulmonary alveolar proteinosis successfully treated with GM-CSF. Thorax. 2002;57:277-80.

18. Hashimoto A, Tanaka T, Itoh Y, Yamagata A, Kitamura N, Tazawa R, Nakagak K, Nakata K. Low concentrations of recombinant granulocyte macrophagecolony stimulating factor derived from Chinese hamster ovary cells augments long-term bioactivity with delayed clearance in vitro. Cytokine. 2014:68:118-26.

19. Suzuki T, Sakagami T, Young LR, Carey BC, Wood RE, Luisetti M, Wert SE, Rubin BK, Kevill K, Chalk C, Whitsett JA, Stevens C, Nogee LM, Campo I, Trapnell BC. Hereditary pulmonary alveolar proteinosis: pathogenesis, presentation, diagnosis, and therapy. Am J Respir Crit Care Med. 2010;182:1292-304.

20. Hildebrandt J, Yalcin E, Bresser HG, Cinel G, Gappa M, Haghighi A, Kiper N, Khalilzadeh S, Reiter K, Sayer J, Schwerk N, Sibbersen A, Van Daele S, Nübling G, Lohse P, Griese M. Characterization of CSF2RA mutation related juvenile pulmonary alveolar proteinosis. Orphanet J Rare Dis. 2014;9:171. 